\title{
Endoscopic Biliary Drainage
} Using Guidewire Cannulation in a Case with Severe Duodenal Stenosis Caused by Duodenal Undifferentiated Carcinoma

\author{
Hiroyuki Matsubayashi ${ }^{a}$ Naomi Kakushima $^{a}$

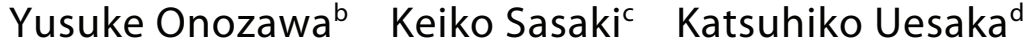 \\ Hiroyuki Onoa \\ Division of a Endoscopy, ${ }^{\mathrm{b}} \mathrm{G}$ astrointestinal Oncology, $\mathrm{cPathology}$ and \\ ${ }^{\mathrm{d} H e p a t o-B i l i a r y-P a n c r e a t i c ~ S u r g e r y, ~ S h i z u o k a ~ C a n c e r ~ C e n t e r, ~ S h i z u o k a, ~ J a p a n ~}$
}

\section{Key Words}

Guidewire · Cannulation · Undifferentiated carcinoma · Biliary drainage

\begin{abstract}
We present a case of duodenal carcinoma, $12 \mathrm{~cm}$ in size, with severe stenosis at the second portion of the duodenum. When the patient developed obstructive jaundice, it was impossible to perform endoscopic biliary drainage by standard cannulation due to the stenosis, but was succeeded by wire-guided cannulation using papillotome. Histology of the tumor showed undifferentiated carcinoma without differentiation to any specific cell type. Systemic chemotherapy was started with 5-FU, leucovorin and oxaliplatin. Biliary stent worked well until the patient succumbed three months after. Herein we demonstrate the new advantage of wire-guided cannulation in case of duodenal stenosis.
\end{abstract}

\section{Background}

Wire-guided cannulation is a recently popular method to facilitate cannulation to the biliary duct during endoscopic retrograde cholangiopancreatography (ERCP) [1-3]. The success rate of biliary cannulation increased by about $20 \%$ of cases [2], however it has not been described in which cases the papillotome cannulation technique is the most advantageous. In case of duodenal stenosis due to massive tumor invasion, it is often difficult to perform ERCP, especially when the tumor involves the periampullary region. 
We report a case in whom endoscopic biliary drainage was successfully performed in spite of severe duodenal stenosis caused by undifferentiated carcinoma.

\section{Case Report}

In July 2008, a 77-year-old woman was referred to our institute for the purpose of examination and therapy for bulky duodenal tumor detected by ultrasonography and upper gastrointestinal endoscopy. She had begun to feel fullness and occasional tarry stool three month before. She had a history of chronic hepatitis type C. Her family history was not remarkable. Abdominal computed tomography (CT) demonstrated a bulky enhanced mass at the second portion of the duodenum, $12 \mathrm{~cm}$ in largest diameter, with a central low-density area suggestive of necrosis (ig. 1). Barium contrast and upper gastrointestinal endoscopy (fig. 2a) showed duodenal stenosis caused by an irregularly margined tumor with central ulceration. Forceps biopsies showed histology of undifferentiated carcinoma (fig. 2b). Immunostaining of the tumor was diffusely positive for vimentin and $\mathrm{Ki}-67$, faintly positive for AE1/AE3, cytokeratin 7 and cytokeratin 19, but negative for alcian blue, PAS, cytokeratin 20, AFP, CD3, CD20, CD34, CD45, CD56, chromogranin A, synaptophysin, HHF35 and c-Kit. Positron emission tomography using ${ }^{18} \mathrm{~F}$-fluorodeoxyglucose showed strong accumulation at the duodenum $\left(\mathrm{SUV}_{\max } 14.7\right)$ but no distant metastasis. However, during waiting for operation, massive ascites appeared and the surgery was canceled. A month later, she developed jaundice (serum bilirubin $8.5 \mathrm{mg} / \mathrm{dl}$ ) and ERCP was performed to insert biliary drainage. Duodenal stenosis had progressed and the ampulla of Vater could not be found in the first $15 \mathrm{~min}$. Clinical images, especially CT scan, were helpful to detect the position of the major papilla near the anal edge of the tumor. Duodenoscope could not keep enough distance from the major papilla and only the pancreatic duct could be accessed by conventional cannulation using a standard catheter (Olympus, PR109Q-1). After changing the catheter to papillotome (Olympus, CleverCut 3V, $7 \mathrm{~mm}$ of nose length) and giving it a hairpin shape (fig. 3a), guidewire cannulation to the bile duct was successful at the first attempt (fig. 3b). A biliary plastic stent (Cook, 8.5Fr, Tannenbaum) was placed (fig. 3c) and serum bilirubin level decreased to $2.7 \mathrm{mg} / \mathrm{dl}$ within three days. Systemic chemotherapy by FOLFOX-6 [4] was started, however due to aggressive tumor progression, the patient succumbed three months later.

\section{Discussion}

We report on the utility of wire-guided cannulation using papillotome to access the biliary duct in a case of duodenal stenosis caused by cancer. It is sometimes difficult to insert a duodenoscope into the stenotic site. Even reaching around the papilla, it is also difficult to find out the orifice of Vater because the cancer invades around the periampullary region, often ulcerative, necrotic and/or oozing. For the first biliary drainage in such a case, we usually try to look carefully at the marginal site of the tumor, as in the current case. If obstructive jaundice has occurred recently, the orifice may be located near the edge of tumor rather than at the center. Other images such as CT, magnetic resonance cholangiopancreatography and ultrasonography may provide information on the location of the papilla orifice by following the pancreaticobiliary duct downstream.

Wire-guided cannulation using papillotome has been reported to facilitate biliary cannulation [1-3]. In a randomized trial by Schwacha et al., initial biliary cannulation was successful in $84 \%$ using papillotome compared with $62 \%$ using a standard cannula $(\mathrm{p}<0.05)$ [2]. Cortas et al. [3] also demonstrated higher cannulation ratio and shorter procedure time by using sphincterotome than by conventional catheterization. In the current case, because of the lack of space between duodenoscope and papilla orifice, cannulation to the bile duct was difficult with the standard catheter only, however easily succeeded by giving the cannula a hairpin shape using papillotome (fig. 3). In case of failure in periampullary biliary drainage using these devices, endoscopic ultrasonography-guided biliary drainage is another candidate for patients with ampullary 
invasion [5]. As the period of stent patency is longer than in standard periampullary drainage [5], this method is worth considering before percutaneous transhepatic biliary drainage when surgical operation is not indicated.

Three forceps biopsies from the tumor uniformly showed histology of undifferentiated carcinoma, without any differentiation to epithelial cell, neuroendocrine cell, lymph-plasma cell, muscular cell, or mesenchymal cell. To date, reports on undifferentiated carcinoma of the duodenum are very rare and only one case [6] was detected by PubMed keyword search. Macroscopic finding by duodenoscopy showed atypical features compared with the standard duodenal carcinoma with abundant whitish and reddish necrotic tissue on the surface, without obvious mucosal carcinoma component (fig. 2). The biological behavior of the tumor was aggressive and chemotherapy by FOLFOX-6 [4] was not effective, showing massive ascites, which is the main contraindication of percutaneous biliary drainage [7] and makes endoscopic bile duct access necessary.

We herein present a case of duodenal undifferentiated carcinoma with severe duodenal stenosis, managed by periampullary biliary drainage using papillotome. In cases with difficulty in accessing the bile duct due to insufficient duodenal space, guidewire cannulation is an effective option.

Fig. 1. Abdominal CT showing a bulky tumor located at the second portion of the duodenum, $12 \mathrm{~cm}$ in largest diameter.

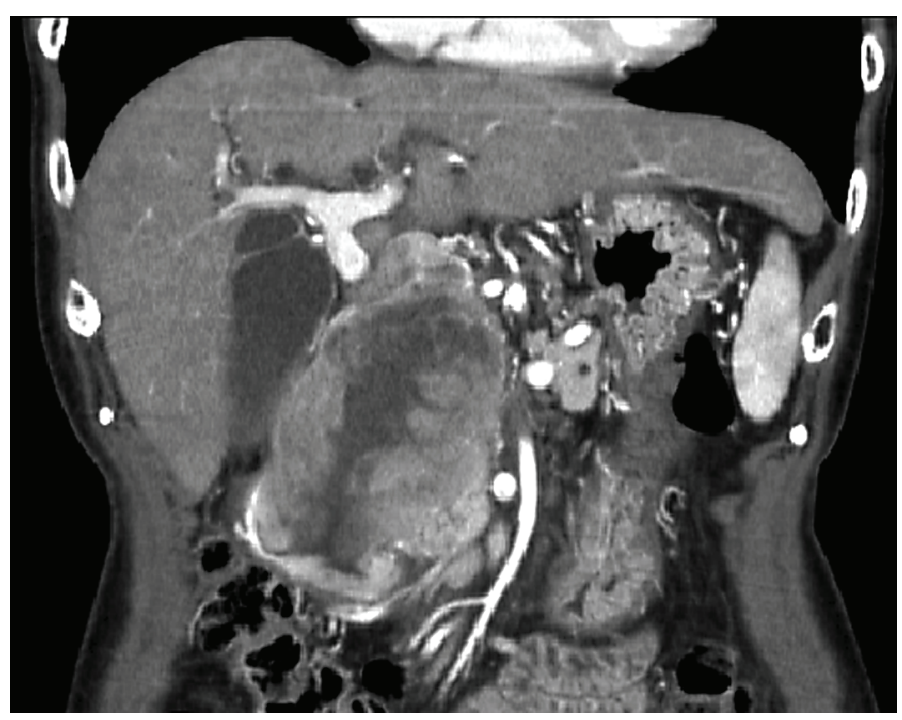




\begin{tabular}{r|l|l|l}
$\begin{array}{r}\text { Case Reports in } \\
\text { Gastroenterology }\end{array}$ & $\begin{array}{l}\text { Case Rep Gastroenterol 2010;4:25-30 } \\
\text { D0I: 10.1159/000254613 }\end{array}$ & Published online: February 3, 2010 & $\begin{array}{l}\text { O 2010 S. Karger AG, Basel } \\
\text { ISSN 1662-0631 } \\
\text { www.karger.com/crg }\end{array}$ \\
\hline
\end{tabular}

Fig. 2. a Endoscopic view of the duodenum showing a large tumor with ulceration and necrosis, and with duodenal stenosis at the second portion. $\mathbf{b}$ Histology of forceps biopsy from the tumor demonstrates undifferentiated carcinoma with abundant inflammatory cell infiltration $(\times 100$, hematoxylin and eosin).
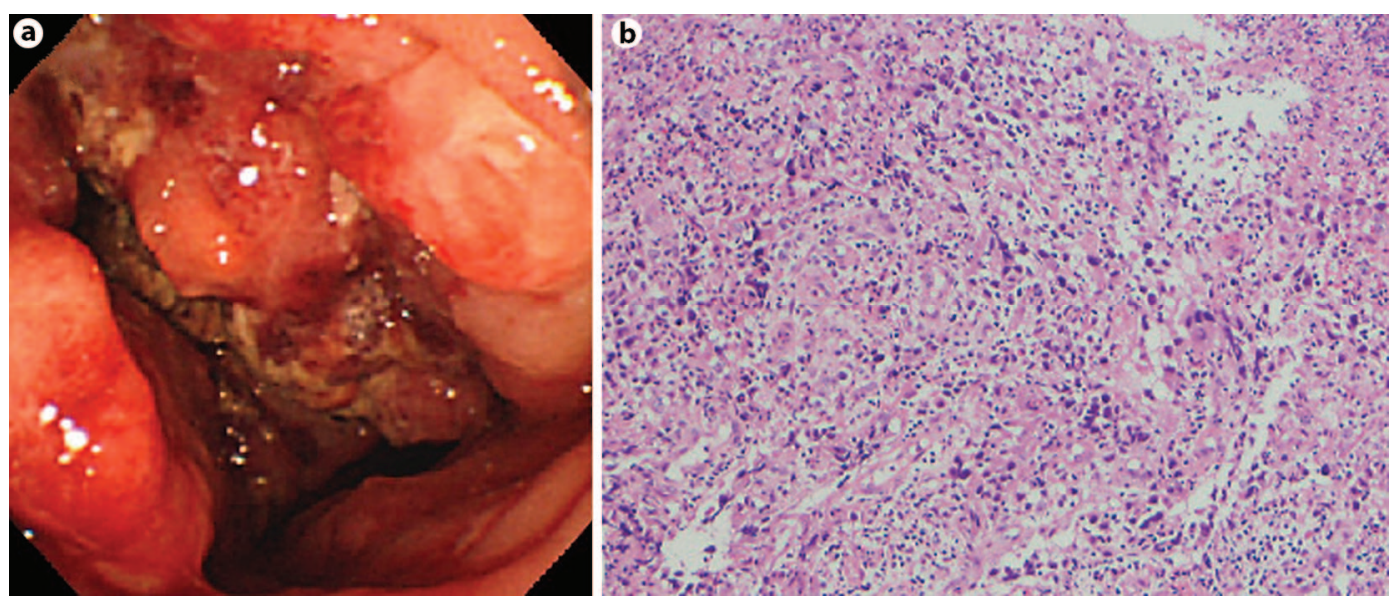
Fig. 3. Guidewire cannulation using papillotome (a), following deep cannulation to the bile duct (b) and biliary stent insertion (c).

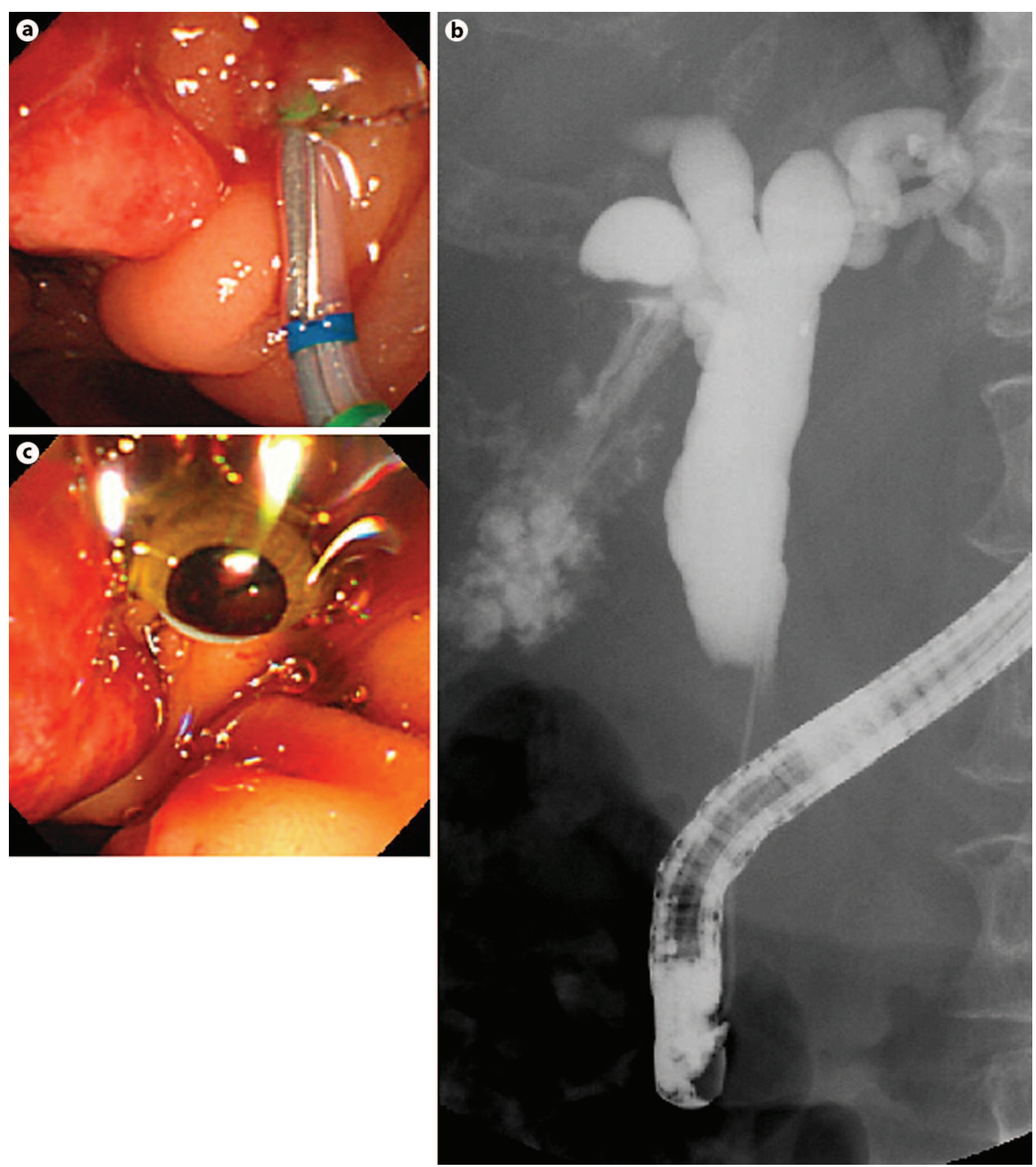




\section{References}

1 Freeman ML, Guda NM: ERCP cannulation: a review of reported techniques. Gastrointest Endosc 2005;61:112-125.

-2 Schwacha H, Allgaier HP, Deibert P, Olschewski M, Allgaier U, Blum HE: A sphincterotome-based technique for selective transpapillary common bile duct cannulation. Gastrointest Endosc 2000;52:387-391.

-3 Cortas GA, Mehta SN, Abraham NS, Barkun AN: Selective cannulation of the common bile duct: a prospective randomized trial comparing standard catheters with sphincterotomes. Gastrointest Endosc 1999;50:775-779.

-4 Maindrault-Goebel F, de Gramont A, Louvet C, et al: Evaluation of oxaliplatin dose intensity in bimonthly leucovorin and 48-hour 5-fluorouracil continuous infusion regimens (FOLFOX) in pretreated metastatic colorectal cancer. Oncology Multidisciplinary Research Group (GERCOR). Ann Oncol 2000;11:1477-1483.

5 Yamao K, Bhatia V, Mizuno N, et al: EUS-guided choledochoduodenostomy for palliative biliary drainage in patients with malignant biliary obstruction: results of long-term follow-up. Endoscopy 2008;40:340-342.

-6 Sato T, Yamamoto K, Ouchi A, Imaoka Y, Tokumura H, Matsushiro T: Undifferentiated carcinoma of the duodenal ampulla. J Gastroenterol 1995;30:517-519.

7 Sparchez Z: Echoguided percutaneous biliary drainage. Indications, performances, complications. Rom J Gastroenterol 2004;13:139-146. 